\title{
Intercalation of Schiff Base Ligands with Copper (II) and Nickel (II) Cation-exchange Montmorillonite (MMT) Nanoclay
}

\author{
Wan Ahmad Kamil Mahmood, ${ }^{1 *}$ Ali Hossein Kianfar, ${ }^{2}$ Mohammad Hossein Azarian, ${ }^{1}$ \\ Nurul Fatin Farhana Ismail ${ }^{1}$ and Sakinah Md Tia ${ }^{1}$ \\ ${ }^{1}$ School of Chemical Sciences, Universiti Sains Malaysia, \\ 11800 USM Pulau Pinang, Malaysia \\ ${ }^{2}$ Department of Chemistry, Isfahan University of Technology, \\ Isfahan 84156-83111, Islamic Republic of Iran \\ *Corresponding author: wakcm@usm.my
}

Published online: 25 November 2016

To cite this article: Mahmood, W. A. K. et al. (2016). Intercalation of Schiff base ligands with Copper (II) and Nickel (II) cation-exchange montmorillonite (MMT) nanoclay. J. Phys. Sci., 27(3), 51-65, http://dx.doi.org/10.21315/jps2016.27.3.4

To link to this article: http://dx.doi.org/10.21315/jps2016.27.3.4

\begin{abstract}
The Schiff bases (E)-3-\{[(2-amino-5-nitrophenyl)imino $]$ methyl $\}$ phenol and (E)-3-\{[(2-amino-5-nitrophenyl)imino]methyl $\}$ benzene-1,2-diol were synthesised from 2,3-dihydroxy-benzaldehyde, salicylaldehyde and 4-nitro-o-phenylenediamine. These ligands were characterised by Fourier transform infrared (FTIR), UV-Visible, CHN analysis, and ${ }^{l} H N M R$. Ni(II) and $\mathrm{Cu}(I I)$ cation-exchange montmorillonite (MMT) clay was prepared by the interactions of $\mathrm{NiCl}_{2}, \mathrm{CuCl}_{2}$ and $\mathrm{MMT}$ clay in an aqueous medium. FTIR and EDX were used to characterise the metal cation-exchange in MMT. Schiff base $\mathrm{Cu}(\mathrm{II})$ and $\mathrm{Ni}(\mathrm{II})$ complexes intercalated montmorillonite were prepared by the interaction of Schiff base ligands and Cu(II) and Ni(II) cation-exchange MMT. Several characterisation techniques, including X-ray diffraction (XRD), transmission electron microscopy (TEM), scanning electron microscopy (SEM), and thermogravimetric analysis (TGA) were used to characterise the modified MMT. SEM results showed that the resulting hybrid had layered structures. The XRD results indicate that the Nickel(II) Schiff base complex-MMT was partially exfoliated.
\end{abstract}

Keywords: Montmorillonite clay (MMT), Schiff base ligand, nanohybrid, exfoliation, metal ions, intercalated-clay 


\section{INTRODUCTION}

Schiff base transition metal complexes can be easily synthesised and have been extensively studied. Schiff base metal complexes have found their applications as catalysts in a wide range of reactions, such as polymerisation, epoxidation of olefins, ring-opening polymerisation, carbonylation reactions and oxidation reactions. ${ }^{1-5}$ Tridentate oxygen-nitrogen-nitrogen (ONN) Schiff base ligands containing anionic amines (RNH) were used to prepare metal Schiff base complexes, ${ }^{6,7}$ while tridentate metal Schiff base complexes were used as catalysts in Heck $^{8}$ and Suzuki-Miyaura cross coupling reactions. ${ }^{9}$

Among the different types of clay, montmorillonite (MMT) has been extensively used for modification due to its excellent properties, such as high cation exchange capacity, swelling behaviour, adsorption properties and its large surface area. ${ }^{10,11}$ The modified montmorillonites are versatile heterogeneous catalysts for a wide variety of organic reactions, such as Friedel-Crafts and oligomerisation reactions. ${ }^{12}$

According to its layer structure, MMT has the potential to host Schiff base metal complexes. Several reports can be found in the literature regarding Schiff base metal complexes immobilised onto MMT clay to prepare nanohybrid materials with improved catalytic properties. For instance, a manganese(II)-Schiff base complex incorporated in the interlayer space of clay minerals exhibits significant catalytic activity. ${ }^{13}$ Parida et al. ${ }^{14}$ have reported the preparation of Schiff base $\mathrm{Pt}(\mathrm{II})$ complex supported MMT by a cation exchange mechanism, and intercalation of the complex inside the clay matrix was confirmed by various characterisation techniques. More recently, we reported the novel nanohybrids of cobalt(III) Schiff base complexes intercalated into MMT clay by a direct exchange reaction of clay and cobalt(III) complexes. ${ }^{15,16}$

Herein, we have extended our previous studies to do an ion-exchange reaction of MMT clay by interacting it with $\mathrm{Cu}$ (II) and $\mathrm{Ni}$ (II) cations. In a follow-up study, metal cation-exchange MMT was reacted with two different Schiff base ligands to perform in-situ synthesis of complexes within the layers of MMT clay. The metal Schiff base complexes intercalated into MMT were identified and studied via FTIR, XRD, TGA/DTG, SEM and TEM. 


\section{EXPERIMENTAL}

\subsection{Chemicals}

All of the chemicals and solvents used for synthesis were of commercially available reagent grade and used without further purification. Montmorillonite K10 (MMT) with cation-exchange capacity of $119 \mathrm{meq} / 100 \mathrm{~g}$ was provided by Aldrich (St. Louis, MO, USA).

\subsection{Synthesis of Schiff Base Ligand $\left(L^{1}\right)$}

The Schiff base ligand, (E)-3-\{[(2-amino-5-nitrophenyl)imino $]$ methyl $\}$ phenol $\left(\mathrm{L}^{1}\right)$, was prepared by adding salicylaldehyde solution $(1 \mathrm{mmol})$ dropwise into 4 nitro-o-phenylenediamine $(1 \mathrm{mmol})$ with stirring. Then, the solution was refluxed for $2 \mathrm{~h}$. During the reaction, a yellow precipitate appeared. The precipitate was filtered and washed with methanol and dried in an oven.

Yield (73.44\%). Theoretical calculation for $\mathrm{C}_{13} \mathrm{H}_{11} \mathrm{~N}_{3} \mathrm{O}_{3}$ : Carbon, $\mathrm{C}(61.67 \%)$, Hydrogen, H (4.31\%), Nitrogen, N (16.32\%). Found: Carbon, C (58.25\%), Hydrogen, $\mathrm{H}(3.83 \%)$, Nitrogen, $\mathrm{N}(15.51 \%)$. FTIR $\left(\mathrm{KBr} \mathrm{cm}^{-1}\right), v_{\max } 3480$ and $3370\left(\mathrm{NH}_{2}\right), 1614(\mathrm{C}=\mathrm{N}), 1490(\mathrm{C}=\mathrm{C})$ and $1325\left(\mathrm{NO}_{2}\right) .{ }^{1} \mathrm{HNMR}(\delta, \mathrm{ppm}): 11.861$ (singlet, $1 \mathrm{H}, \mathrm{OH}$ ), 8.984 (singlet, $1 \mathrm{H}, \mathrm{C}=\mathrm{N}$ ), Aromatic rings: 7.970 (singlet, $1 \mathrm{H}$ ), 7.941-7.952 (doublet, 1H), 7.822-7.837 (doublet, 1H), 7.418-7.449 (triplet, 1H), 6.979-6.995 (doublet, 1H), 6.808-6.821 (doublet, 1H), 6.682 (singlet, $2 \mathrm{H}, \mathrm{NH}_{2}$ ). UV-Vis, $\lambda_{\text {max }}(\mathrm{nm})$ (Ethanol): 374, 205 and 250.

\subsection{Synthesis of Schiff Base Ligand $\left(\mathrm{L}^{2}\right)$}

The Schiff base ligand, (E)-3-\{[(2-amino-5-nitrophenyl)imino $]$ methyl $\}$ benzene1,2-diol $\left(\mathrm{L}^{2}\right)$, was prepared by adding 2,3-dihydroxy-benzaldehyde $(1 \mathrm{mmol})$ dropwise into 4-nitro-o-phenylenediamine $(1 \mathrm{mmol})$ with stirring. The remainder of the synthesis process is similar to $\mathrm{L}^{1}$ except that an orange precipitate was obtained.

Yield (94.14\%) CHN: Theoretical calculation for $\mathrm{C}_{13} \mathrm{H}_{11} \mathrm{~N}_{3} \mathrm{O}_{4}$ : Carbon, C (57.14\%), Hydrogen, H (4.06\%), Nitrogen, N (15.37\%) Found: Carbon, C (58.31\%), Hydrogen, $\mathrm{H}(4.61 \%)$, Nitrogen, $\mathrm{N}(13.52 \%)$. FTIR $\left(\mathrm{KBr} \mathrm{cm}^{-1}\right)$ : $v_{\max }$ 3494 and $3386\left(\mathrm{NH}_{2}\right), 1620(\mathrm{C}=\mathrm{N}), 1490(\mathrm{C}=\mathrm{C})$, and $1344\left(\mathrm{NO}_{2}\right) .{ }^{1} \mathrm{HNMR}(\delta$, ppm): 11.833 (singlet, $1 \mathrm{H}, \mathrm{OH}$ ), 9.313 (singlet, $1 \mathrm{H}, \mathrm{OH}$ ), 8.950 (singlet, $1 \mathrm{H}$, $\mathrm{C}=\mathrm{N}$ ), Aromatic Rings: 7.965 (singlet, 1H), 7.942-7.948 (doublet, 1H), 7.233-7.236 (doublet, 1H), 6.981-6.984 (doublet, 1H), 6.807-6.825 (triplet, 2H), 6.689 (singlet, $2 \mathrm{H}, \mathrm{NH}_{2}$ ). UV-Vis, $\lambda_{\max }(\mathrm{nm})$ (Ethanol): 372,280 and 207. 


\subsection{Preparation of $\mathrm{Cu}(\mathrm{II})$ and $\mathrm{Ni}(\mathrm{II})$ Cation-exchange MMT}

Two saturated solutions of cupric(II) chloride and nickel(II) chloride were prepared by dissolving $10.439 \mathrm{~g}$ and $10.900 \mathrm{~g}$ in $10 \mathrm{ml}$ of distilled water, respectively. The solutions were transferred into two round-bottom flasks followed by the addition of $0.500 \mathrm{~g}$ montmorillonite K10 clay (MMT) into each flask. The solutions were refluxed for $4 \mathrm{~h}$ and then filtered through a Buchner funnel and washed with plenty of distilled water.

FTIR (KBr cm$\left.{ }^{-1}\right) v_{\max }$ pure clay (MMT): 3441 (HO stretching of water), 1636 ( $\mathrm{HOH}$ deformation vibration), 1071 ( $\mathrm{Si}-\mathrm{O}$ stretching vibration), 526 ( $\mathrm{Si}-\mathrm{O}-\mathrm{Al}$ bending vibrations), 469 ( $\mathrm{Si}-\mathrm{O}-\mathrm{Si}$ bending vibrations).

FTIR $\left(\mathrm{KBr} \mathrm{cm}^{-1}\right) v_{\max } \mathrm{Cu}$ (II) and Ni(II) cation-exchange MMT: 3450 and 3444 (HO stretching of water), 1635 (HOH deformation vibrations), 1080 and 1071 ( $\mathrm{Si}-\mathrm{O}$ stretching vibrations), 528 and 527 ( $\mathrm{Si}-\mathrm{O}-\mathrm{Al}$ bending vibrations) and 474 ( $\mathrm{Si}-\mathrm{O}-\mathrm{Si}$ bending vibrations).

\subsection{Intercalation of Schiff Base Ligands $\left(L^{1}\right)$ and $\left(L^{2}\right)$ into $\mathrm{Cu}(\mathrm{II})$ and Ni(II) Cation-exchange Montmorillonite}

A total of $0.060 \mathrm{~g}$ of each ligand separately dissolved in $15 \mathrm{ml}$ of methanol. A total of $0.400 \mathrm{~g}$ of $\mathrm{Cu}(\mathrm{II})$ and $\mathrm{Ni}(\mathrm{II})$ cation-exchange MMT were added into Schiff base solutions and refluxed for $4 \mathrm{~h}$. The dark orange and light grey precipitates were filtered through a Buchner funnel and washed several times with methanol and distilled water. The collected products were dried in the oven and stored in desiccators.

FTIR $\left(\mathrm{KBr} \mathrm{cm}^{-1}\right) v_{\max } 3453$ (HO stretching of water), $1619(\mathrm{C}=\mathrm{N}), 1575$ and 1465 $(\mathrm{C}=\mathrm{C}),\left(1334\left(\mathrm{NO}_{2}\right), 1079(\mathrm{Si}-\mathrm{O}\right.$ stretching vibration), $524(\mathrm{Si}-\mathrm{O}-\mathrm{Al}$ bending vibrations), 468 ( $\mathrm{Si}-\mathrm{O}-\mathrm{Si}$ bending vibrations).

FTIR $\left(\mathrm{KBr} \mathrm{cm}^{-1}\right) v_{\text {max }} 3438$ (HO stretching of water), 3018, 2926, 2861, (C-H), $1609(\mathrm{C}=\mathrm{N}), 1493$ and $1454(\mathrm{C}=\mathrm{C}), 1079(\mathrm{Si}-\mathrm{O}$ stretching vibrations), 525 ( $\mathrm{Si}-\mathrm{O}-\mathrm{Al}$ bending vibrations) and 471 ( $\mathrm{Si}-\mathrm{O}-\mathrm{Si}$ bending vibrations).

\subsection{Characterisations}

Infrared (FTIR) spectra were recorded as KBr discs on a PERKIN ELMER 2000 FTIR spectrophotometer in the range of $4000-400 \mathrm{~cm}^{-1}$. The elemental analysis was determined using a CHN Analyzer, model PERKIN ELMER II. UV-Vis spectra were recorded on a UV-2600 Shimadzu spectrophotometer in the 190-900 
$\mathrm{nm}$ range. The ${ }^{1} \mathrm{H}$ NMR spectra were recorded on a Bruker $500 \mathrm{MHz}$ ultrashield $^{\mathrm{TM}}$ spectrometer. The X-ray diffraction (XRD) was recorded on a high resolution X-ray diffractometer system model PAnalytical X'PERT PRO MRD PW3040. Transmission Electron Microscopy (TEM) study was performed using a FEI/PHILIPS CM12, thickness and silicate layer spacing were recorded using Olympus image analysis software. The thermal stability of specimens was tested using a TGA/SDTA851 Thermo Gravimetric analyser from ambient temperature to $900^{\circ} \mathrm{C}$ with a heating rate of $20^{\circ} \mathrm{C} \mathrm{min}^{-1}$ under nitrogen gas. Scanning Electron Microscopy (SEM) was recorded on a QUANTA FEG 6502012 SEM system. Energy Dispersive X-ray Analysis (EDX) (EDAX Falcon System) was conducted to analyse the presence of elements in the specimens.

\section{RESULTS AND DISCUSSION}

\section{1 $\quad$ FTIR Characteristics}

The $\mathrm{C}=\mathrm{N}$ stretching frequency for $\mathrm{L}^{1}$ and $\mathrm{L}^{2}$ exists at 1620 and $1614 \mathrm{~cm}^{-1}$, respectively. The $\mathrm{NO}_{2}$ vibrational frequency presence at $1325 \mathrm{~cm}^{-1}$ is for $\mathrm{L}^{1}$ and $1344 \mathrm{~cm}^{-1}$ is for $\mathrm{L}^{2}$. Both metal(II) cation-exchange MMT products showed peaks related to their functional groups (Figure 1). A broad peak was observed in the range of $3600-3200 \mathrm{~cm}^{-1}$, which can be attributed to the interlayer absorbed water molecules. A weak band appeared at $1635 \mathrm{~cm}^{-1}$, which is related to the $\mathrm{OH}$ bending of these water molecules. The $\mathrm{Si}-\mathrm{O}$ stretching peak appears in the range of $1300-900 \mathrm{~cm}^{-1}$. The peaks at 474 and 528 for $\mathrm{Cu}(\mathrm{II})$ cation-exchange MMT and 527 for $\mathrm{Ni}(\mathrm{II})$ cation-exchange $\mathrm{MMT}$ are due to $\mathrm{Mg}-\mathrm{O}$ and $\mathrm{Al}-\mathrm{O}$, respectively. 


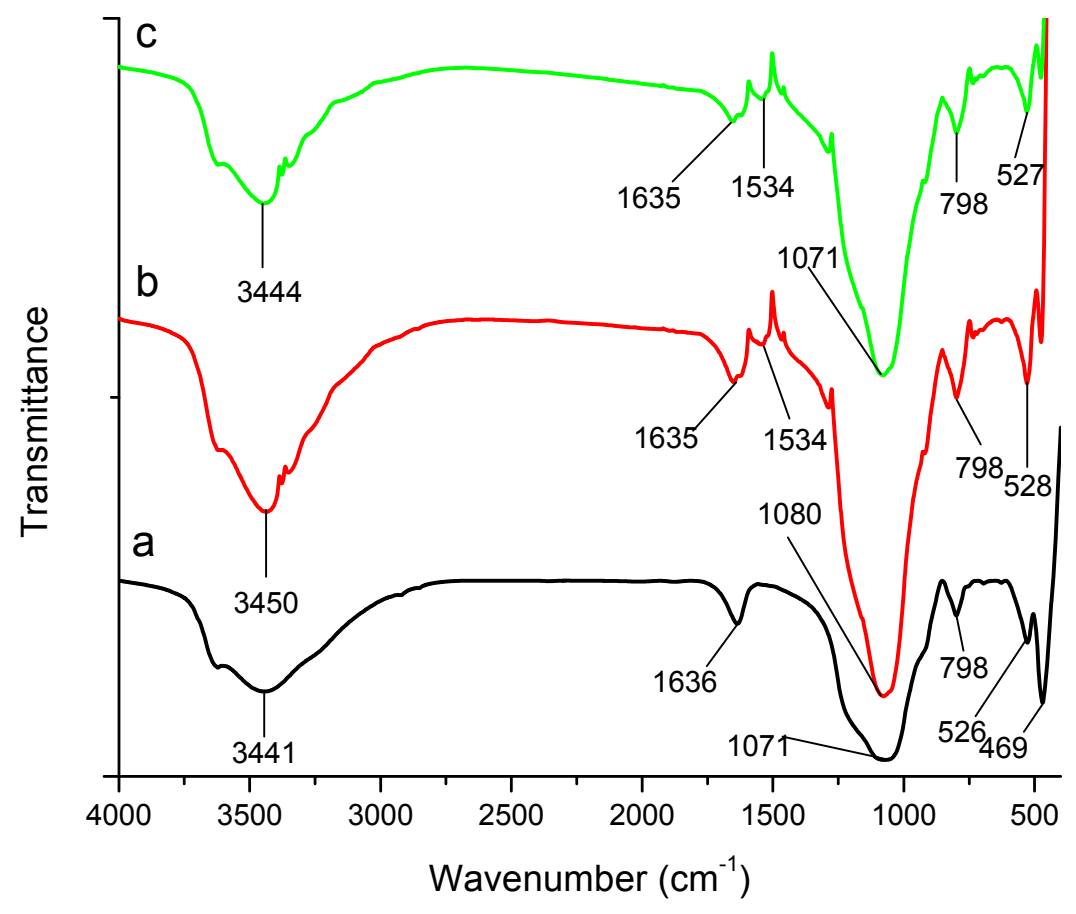

Figure 1: FTIR spectra of a) pure clay b) Ni(II) cation-exchange MMT, c) $\mathrm{Cu}(\mathrm{II})$ cationexchange MMT.

The FTIR spectra for the intercalation of Schiff base ligands into metal(II) cation-exchange MMT showed some differences compared to the pure MMT (Figure 2). Some peaks that are related to the metal Schiff base complexes were observed in the new intercalation compounds. The $\mathrm{C}=\mathrm{N}$ band appears at approximately $1600 \mathrm{~cm}^{-1}$. Theoretically, the $\mathrm{C}=\mathrm{N}$ band is predicted to shift to a lower frequency (blue shift) relative to the free Schiff base. From the experiment, the imine band of the Ni(II) Schiff base intercalated MMT is shifted to a lower frequency at $1609 \mathrm{~cm}^{-1}$. However, the imine band of the $\mathrm{Cu}$ (II) Schiff base intercalated MMT shifted to a higher frequency (red shift) at $1619 \mathrm{~cm}^{-1}$ due to a decrease in repulsion between the nitrogen lone pair of electrons as a result of their participation in coordination with the metal ion. ${ }^{17}$ 


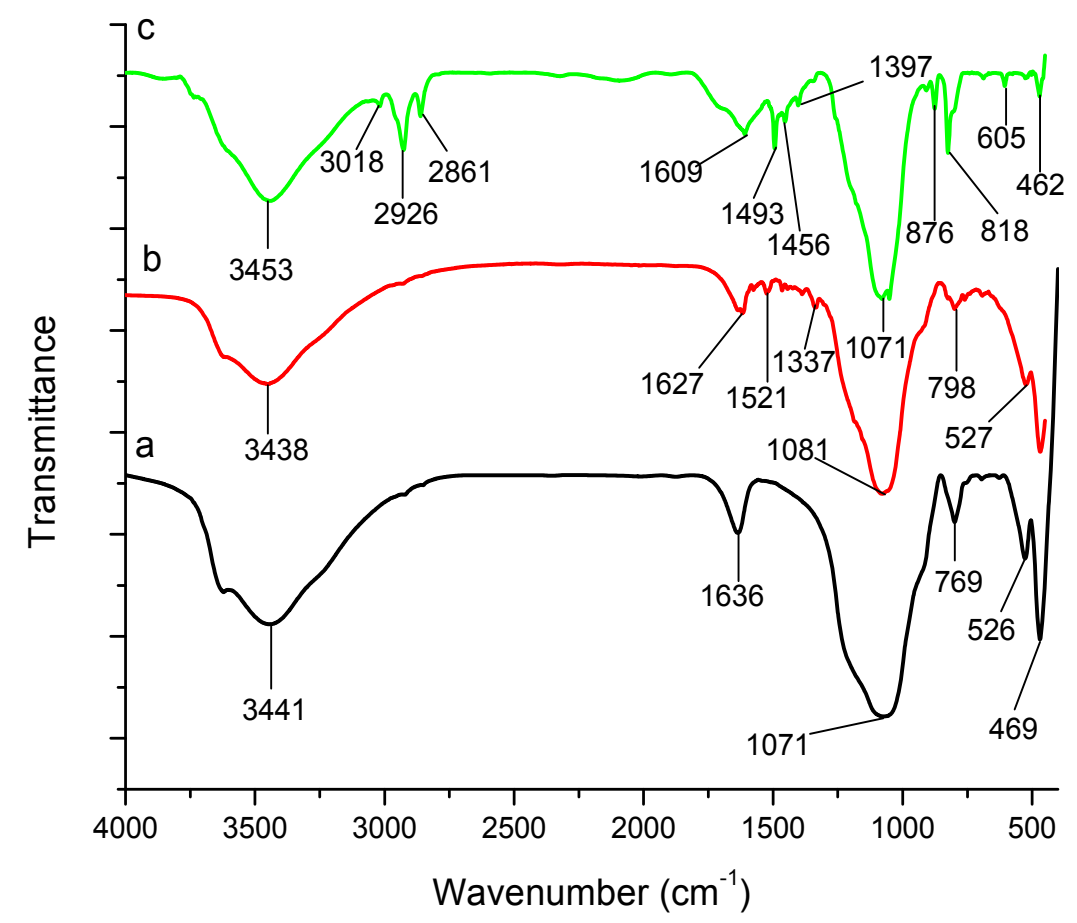

Figure 2: FTIR spectra of a) pure clay b) Schiff base Ni(II) complex intercalated MMT MMT and c) Schiff base Cu(II) complex intercalated.

\subsection{XRD Analysis}

The XRD analysis confirmed that the intercalation and partial exfoliation of the MMT were successful with the cationic complexes. The d-spacing of unmodified MMT $(\mathrm{d}=1.006 \mathrm{~nm})$ is calculated from the peak position at $2 \theta=8.78$ using Bragg's equation. The diffraction peak of Ni(II) Schiff base intercalated MMT nanohybrid decreased and shifted to a new position at $2 \theta=8.073(\mathrm{~d}=1.095 \mathrm{~nm})$. The $\mathrm{Cu}(\mathrm{II})$ Schiff base intercalated MMT shifted to a new position at $2 \theta=7.448$ $(\mathrm{d}=1.187 \mathrm{~nm})$ after the ion exchange reaction between MMT and the cationic complexes (Figure 3). The Ni(II) Schiff base intercalated MMT was partially exfoliated since the $\mathrm{d}$ basal distance almost disappeared, but it still had layered structures. The intercalated reaction and partial exfoliation of MMT occurred because of increases in the interlayer distance, which leads to a shift of the diffraction peak towards lower angles followed by increasing basal distances. 


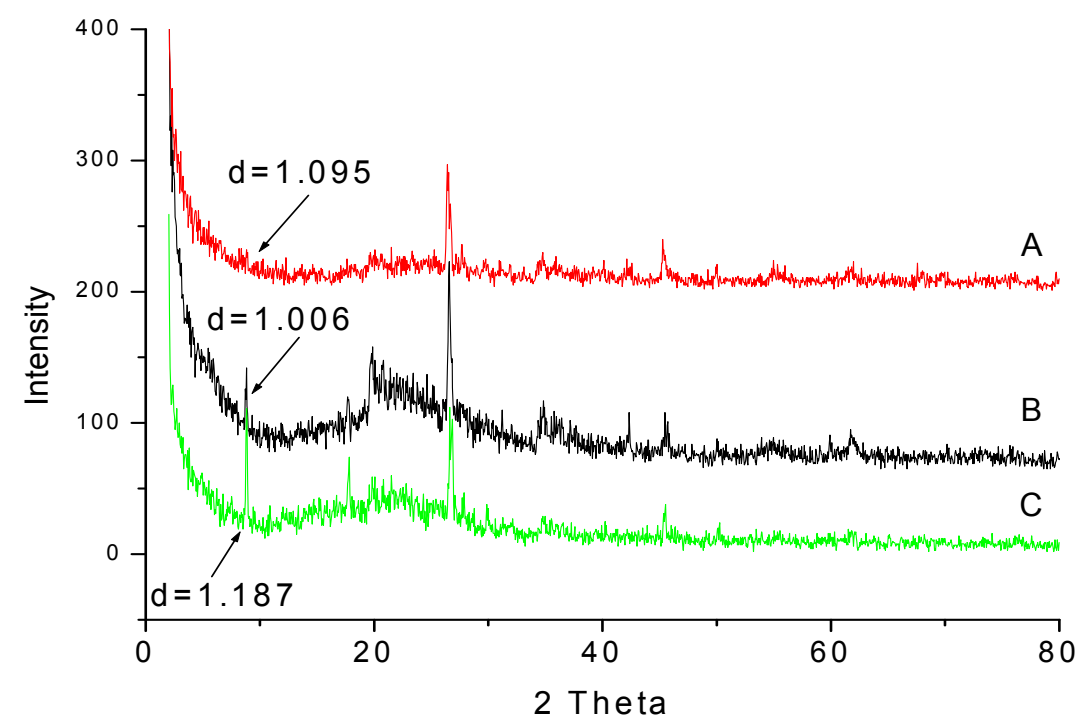

Figure 3: The XRD patterns of the hybrid materials of (A) Ni(II) Schiff base complex intercalated MMT, (B) pure MMT, (C) $\mathrm{Cu}(\mathrm{II})$ Schiff base complex intercalated MMT.

\subsection{Morphology}

The SEM images of the intercalated $\mathrm{Ni}(\mathrm{II})$ and $\mathrm{Cu}(\mathrm{II})$ Schiff base complexes in MMT were observed using SEM technique (Figure 4). The SEM images for $\mathrm{Ni}$ (II) and $\mathrm{Cu}$ (II) Schiff base intercalated MMT showed layered structures. Figure 5(i) and Figure 5(ii) show the EDX spectrum of $\mathrm{Ni}$ (II) and $\mathrm{Cu}(\mathrm{II})$ cationexchange MMT particles, respectively. In the EDX spectrum, the following six elements can be observed: oxygen $(\mathrm{O})$, magnesium $(\mathrm{Mg})$, aluminium $(\mathrm{Al})$, potassium $(\mathrm{K})$, silicon $(\mathrm{Si})$, nickel $(\mathrm{Ni})$ and copper $(\mathrm{Cu})$ in $\mathrm{Ni}(\mathrm{II})$ cation-exchange MMT or $\mathrm{Cu}(\mathrm{II})$ cation-exchange MMT. The presence of elemental nickel and copper confirmed that the cation-exchange of the MMT clay with metal ions had occurred successfully. 

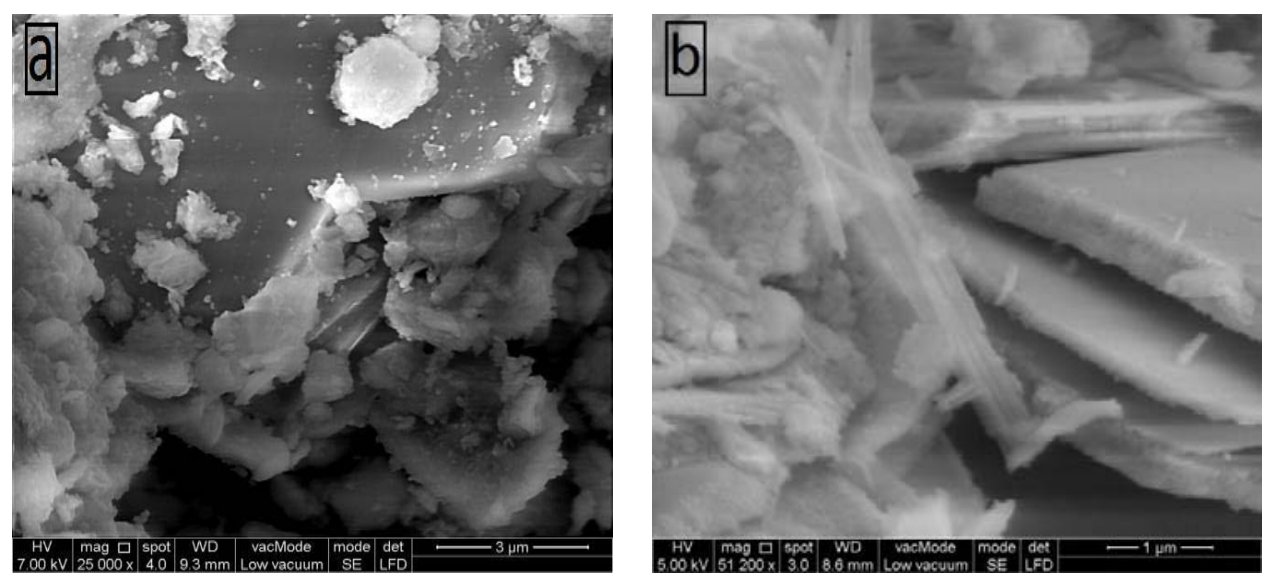

Figure 4: SEM images of (a) Cu(II) Schiff base intercalated MMT complexes and (b) Ni(II) Schiff base intercalated MMT complexes.

TEM images of $\mathrm{Ni}(\mathrm{II})$ and $\mathrm{Cu}(\mathrm{II})$ Schiff base intercalated MMT nanohybrid are shown in Figure 6. According to the TEM images, the thickness of the silicate layers of the clay is in a range of $2-5 \mathrm{~nm}$, and no aggregation was observed in the TEM images. The space between the silicate layers is approximately $2 \mathrm{~nm}$. 

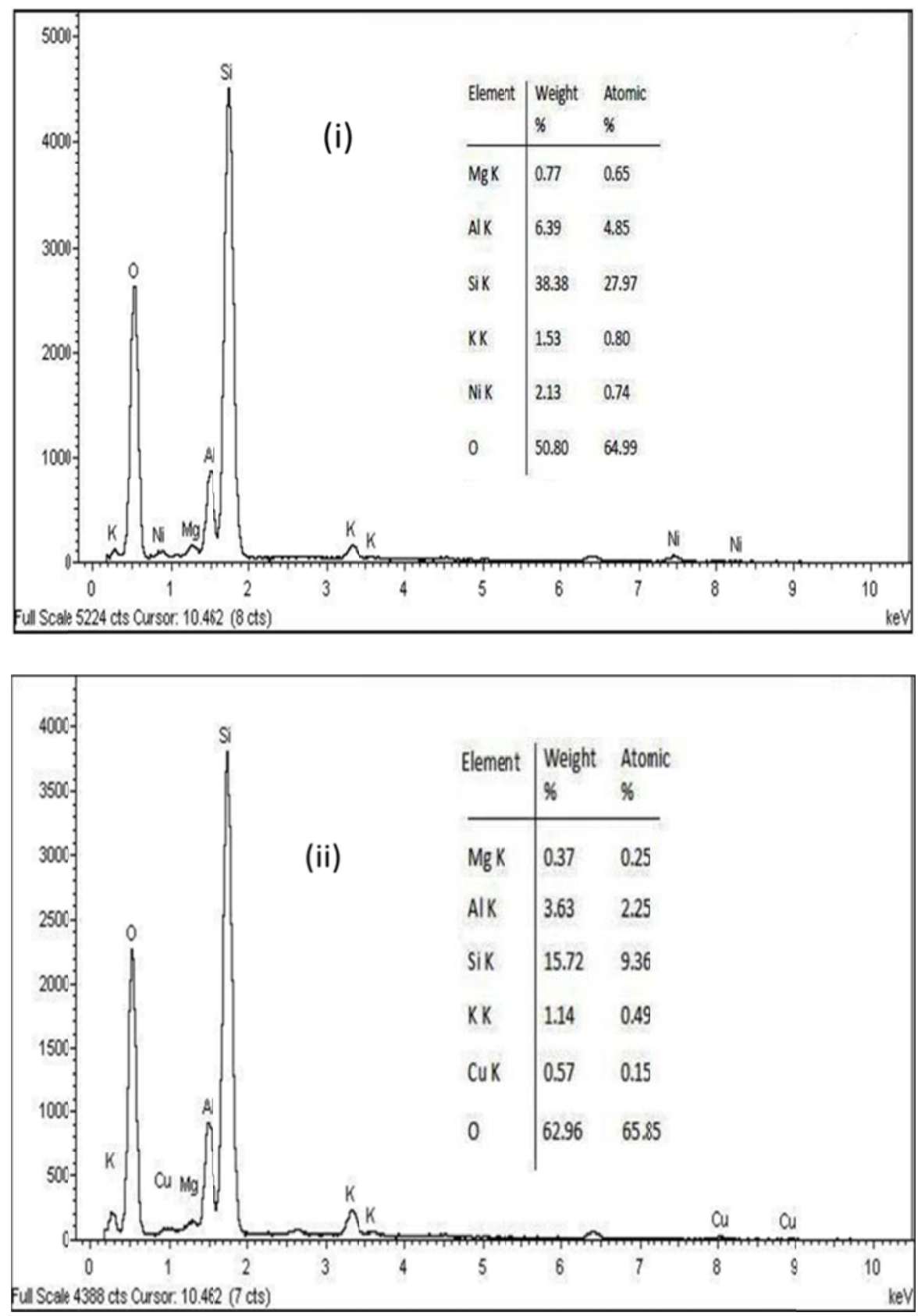

Figure 5: (i) The EDX of Ni(II) cation-exchange MMT; (ii) The EDX of $\mathrm{Cu}$ (II) cationexchange MMT. 

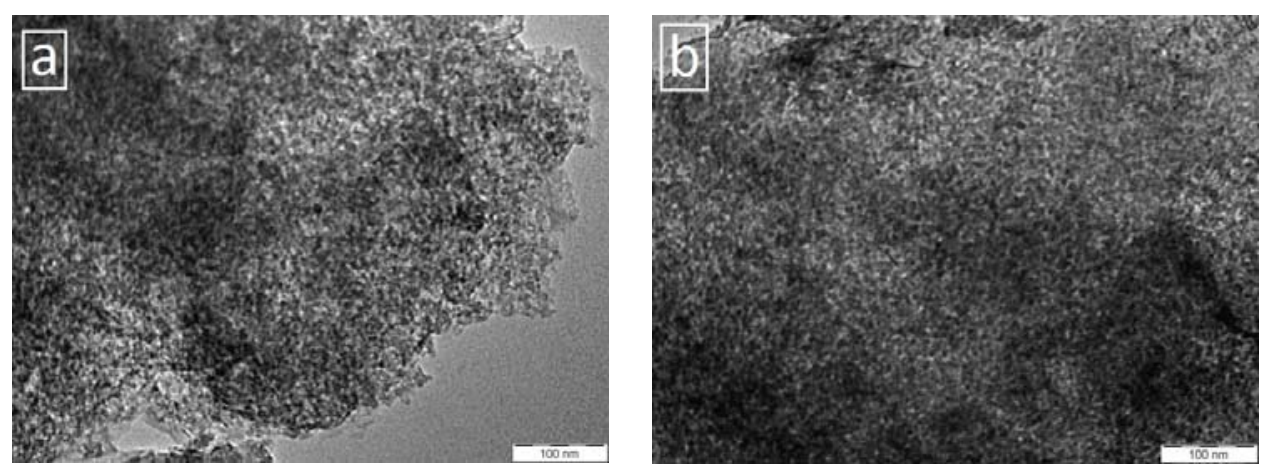

Figure 6: The TEM images of a) Cu(II) Schiff base intercalated MMT; and b) Ni(II) Schiff base intercalated MMT.

\subsection{Thermal Analysis}

TGA and DTG curves of MMT, Ni(II) and Cu(II) Schiff base intercalated MMT are shown in Figure 7 and Figure 8. The thermal analysis of the clay (MMT) shows that the main weight losses $(5.90 \%)$ occur at a temperature of $30^{\circ} \mathrm{C}$ to $270^{\circ} \mathrm{C}$, which can be attributed to the loss of physically adsorbed water. Second mass losses $(1.90 \%)$ in the range of $270^{\circ} \mathrm{C}$ to $560^{\circ} \mathrm{C}$ correspond to the loss of water that is bonded to the clay layers. The final weight loss is $2.20 \%$, which is due to the loss of the hydroxyl groups of the clay. Decomposition of $\mathrm{Ni}(\mathrm{II})$ and $\mathrm{Cu}$ (II) Schiff base intercalated MMT compounds occurred in three steps. In $\mathrm{Ni}$ (II) Schiff base intercalated MMT, the mass loss (6.39\%) at room temperature to $235^{\circ} \mathrm{C}$ is due to the adsorbed water. The second decomposition step $(5.11 \%)$, which started at $235^{\circ} \mathrm{C}$ and ended at $702^{\circ} \mathrm{C}$, is due to decomposition of Schiff base complexes that intercalated to the clay layers. In the case of $\mathrm{Cu}$ (II) Schiff base intercalated MMT, the first step started from room temperature to $166^{\circ} \mathrm{C}$ with a mass loss of $3.83 \%$. The second step shows $5.49 \%$ weight loss at the temperature of $166^{\circ} \mathrm{C}$ to $478^{\circ} \mathrm{C}$. The weight loss in the third step is $2.90 \%$ and $9.45 \%$ for $\mathrm{Ni}(\mathrm{II})$ and $\mathrm{Cu}(\mathrm{II})$ Schiff base intercalated MMT, respectively. The residue for $\mathrm{Ni}(\mathrm{II})$ Schiff base intercalated $\mathrm{MMT}$ and $\mathrm{Cu}(\mathrm{II})$ Schiff base intercalated MMT is approximately $86.00 \%$ and $81.23 \%$, respectively. 


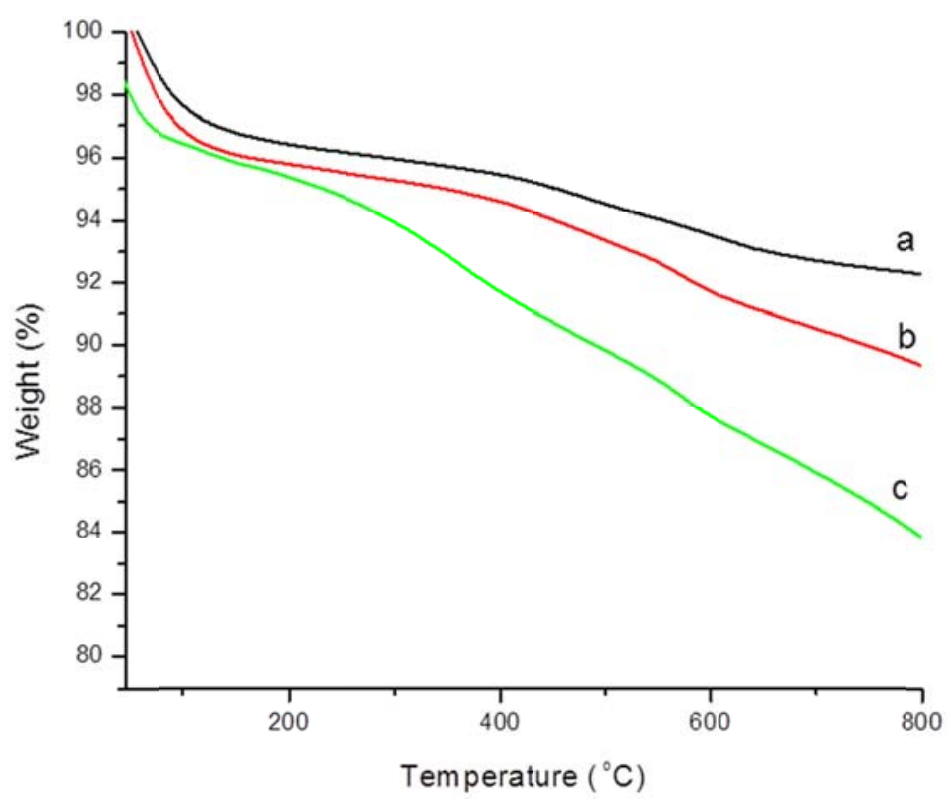

Figure 7: TGA thermograph of a) pure clay, b) Schiff base Ni((II) complex intercalated MMT, and c) Schiff base Cu((II ) complex intercalated MMT.

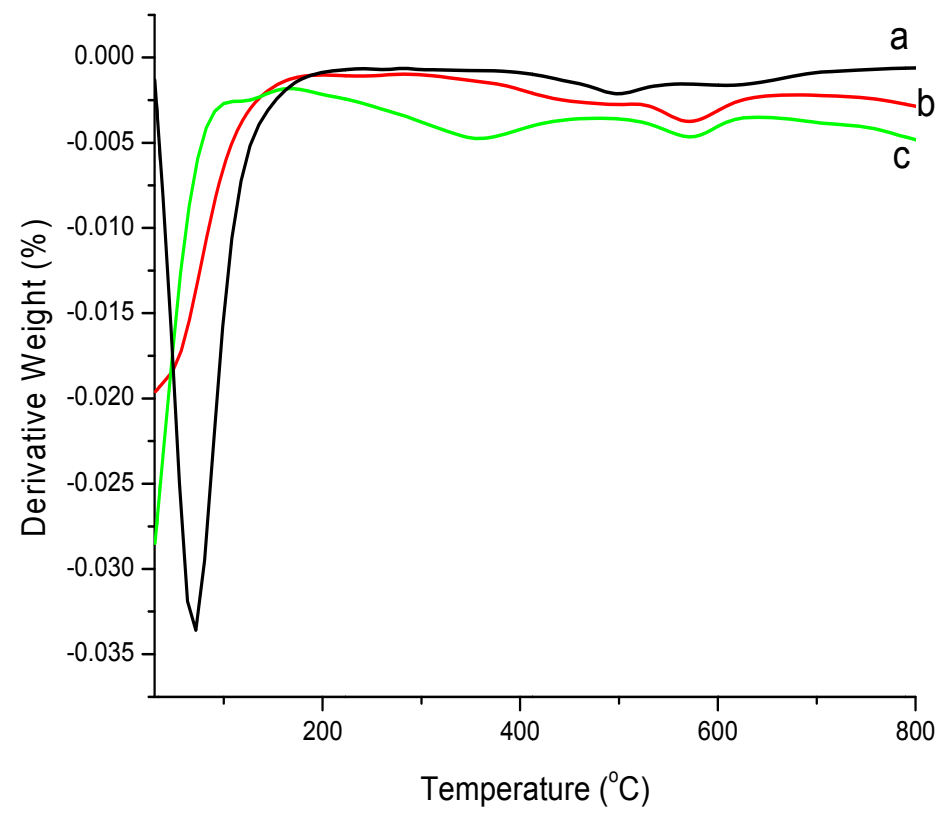

Figure 8: DTG thermograph of: a) Pure clay, b) Schiff base Ni(II) complex intercalated MMT, and c) Schiff base Cu(II) complex intercalated MMT. 


\section{CONCLUSION}

Two metal Schiff base complexes, copper(II)(E)-3-\{[(2-amino-5-nitrophenyl) imino]methyl $\}$ phenol and nickel(II)(E)-3-\{[(2-amino-5-nitrophenyl)imino] methyl benzene-1,2-diol were synthesised by an in-situ generation of complexes inside the layers of MMT clay. FTIR, TGA/DTG, XRD, TEM and SEM were used to characterise the resulting $\mathrm{Cu}$ (II) and Ni(II) Schiff base intercalated MMT. A TEM micrograph showed that the thickness of the nanoparticle layers is less than $5 \mathrm{~nm}$ (Figure 9). The XRD spectrum of the Ni(II) Schiff base intercalated MMT showed that the MMT clay was partially exfoliated, and the layered structure of the metal Schiff base intercalated MMT was clearly observed by SEM.

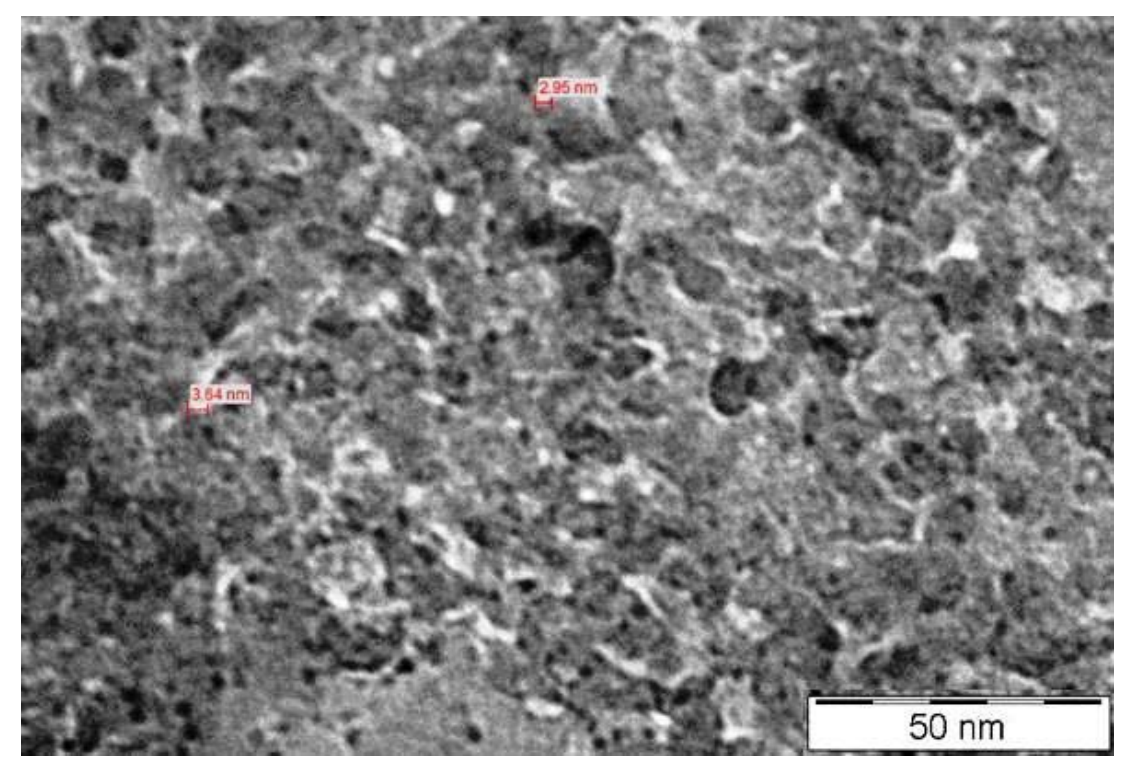

Figure 9: High magnification TEM image of $\mathrm{Cu}(\mathrm{II})$ Schiff base intercalated MMT clay.

\section{ACKNOWLEDGEMENT}

Mohammad Hossein Azarian gratefully acknowledges Universiti Sains Malaysia for financial support Post Graduate Research Grant Scheme (PRGS: 1001.PKIMA.846015) and Fundamental Research Grant Scheme (FRGS: 203.PKIMIA.6711421) from the Ministry of Education. 


\section{REFERENCES}

1. Seitz, M. \& Alt H. G. (2006). Transition metal complexes of polymeric Schiff bases as catalyst precursors for the polymerization of ethylene. J. Mol. Catal. A Chem., 257(1-2), 73-77, http://dx.doi.org/10.1016/ j.molcata.2006.06.039.

2. Kuźniarska-Biernacka, I. et al. (2011). Epoxidation of olefins catalyzed by manganese(III) salen complexes grafted to porous heterostructured clays. Appl. Clay Sci., 53(2), 195-203, http://dx.doi.org/10.1016/ j.clay.2010.12.017.

3. Yao, L. et al. (2012). Ring opening polymerization of 1-lactide by an electron-rich Schiff base zinc complex: An activity and kinetic study. $J$. Mol. Catal. A Chem., 352, 57-62, http://dx.doi.org/10.1016/j.molcata. 2011.10.012.

4. Li-Juana, C., Mei, F.-M. \& Guang-Xing, L. (2009). Co(II) Schiff base complexes on silica by sol-gel method as heterogeneous catalysts for oxidative carbonylation of aniline. Catal. Commun., 10, 981-985.

5. Gupta, K. C., Kumar Sutar, A. \& Lin, C-C. (2009). Polymer-supported Schiff base complexes in oxidation reactions. Coord. Chem. Rev., 253(13-14), 1926-1946, http://dx.doi.org/10.1016/j.ccr.2009.03.019.

6. Kianfar A. H \& Ebrahimi, M. (2013). Synthesis, characterization and structural determination of some nickel(II) complexes containing imido Schiff bases and substituted phosphine ligands. Spectrochim. Acta A Mol. Biomol., 115, 725-729.

7. Kianfar, A. H. et al. (2013). Synthesis, spectroscopy, electrochemistry and thermal study of vanadyl tridentate Schiff base complexes: Theoretical study of the structures of compounds by ab initio calculations. J. Iran. Chem. Soc., 10, 347-355.

8. Pattanayak, P. et al (2013). Synthesis, characterization, structure, redox property, antibacterial and catalytic activity of tridentate Schiff base cobalt(III), nickel(II) and palladium(II) complexes. Polyhedr. 51, 275-282. http://dx.doi.org/10.1016/j.poly.2013.01.010.

9. Tamizha, M. M. et al. (2013). Palladium(II) complexes with salicylideneimine based tridentate ligand and triphenylphosphine: Synthesis, structure and catalytic activity in Suzuki-Miyaura cross coupling reactions. Inorg. Chim. Acta, 394, 391-400.

10. de Paiva, L. B, Morales, A. R. \& Díaz, F. R. V. (2008). Organoclays: Properties, preparation and applications. Appl Clay Sci., 42(1-2), 8-24. http://dx.doi.org/10.1016/j.clay.2008.02.006.

11. Kaur, N, \& Kishore, D. (2012). Montmorillonite: An efficient, heterogeneous and green catalyst for organic synthesis. J. Chem. Pharm. Res., 4(2), 991-1015. 
12. Varma, R. S. (2002). Clay and clay-supported reagents in organic synthesis. Tetrahedr., 58(7), 1235-1255. http://dx.doi.org/10.1016/ S0040-4020(01)01216-9.

13. Gournis, D. et al. (2002). Heterogeneous clay-manganese(II) oxidation catalyst. Mater. Sci. Eng. C, 22(1), 113-116. http://dx.doi.org/10.1016/ S0928-4931(02)00104-2.

14. Parida, K. et al. (2011). Schiff base Pt(II) complex intercalated montmorillonite: A robust catalyst for hydrogenation of aromatic nitro compounds at room temperature. Ind. Eng. Chem. Res., 50(13), 78497856, http://dx.doi.org/10.1021/ie200128w.

15. Kianfar, A. H. et al. (2014). Novel nanohybrids of cobalt(III) Schiff base complexes and clay: Synthesis and structural determinations. Spectrochim Acta A Mol. Biomol. Spectr., 127, 422-428. http://dx.doi.org/10.1016/j.saa.2014.02.089.

16. Kianfar, A. H. et al. (2015). Immobilization of cobalt(III) Schiff base complexes onto Montmorillonite-K10: Synthesis, experimental and theoretical structural determination. Spectrochim. Acta A Mol. Biomol. Spectr., 136, 1582-1592. http://dx.doi.org/10.1016/j.saa.2014.10.051.

17. Khoo, T-J. et al. (2014). Synthesis, characterization and biological activity of two Schiff base ligands and their nickel(II), copper(II), zinc(II) and cadmium(II) complexes derived from S-4-picolyldithiocarbazate and X-ray crystal structure of cadmium(II) complex derived from pyridine-2carboxaldehyde. Inorg. Chim. Acta, 413, 68-76, http://dx.doi.org/ 10.1016/j.ica.2014.01.001. 